\title{
Pescadores artesanais da Bacia de Campos: a saúde pela perspectiva da (in)segurança alimentar
}

\author{
Fishermen in Bacia de Campos: \\ health from the perspective of food (in)security
}

Mauro Macedo Campos

Moisés Machado

Geraldo Márcio Timóteo

Paulo Belchior Mesquita

\section{Resumo}

Este artigo parte do pressuposto de que a Segurança Alimentar e Nutricional (SAN) é uma condição básica para uma vida saudável. Alimentação regular, em quantidade suficiente e com qualidade, é o primeiro passo contra a morbidade ou os fatores que levam ao adoecimento e à morte. A pesquisa de campo analisou as condições de SAN da população de pescadores artesanais de sete municípios localizados na Bacia de Campos. Os achados são preocupantes. Não condizem com os recursos recebidos pelos municípios, em termos de royalties e participações especiais, que se somam a outros repasses e fontes de arrecadação. Chama à atenção a urgência de programas de abastecimento alimentar. Os dados fazem parte do Projeto Pescarte, uma parceria entre UENF/Petrobras/lbama.

Palavras-chave: recursos públicos municipais; pescadores artesanais; segurança alimentar e nutricional; insegurança alimentar; saúde dos pescadores.

\begin{abstract}
This article assumes that Food and Nutrition Security is a basic condition for a healthy life. Regular food in sufficient quantity and quality is the first step against morbidity, or against factors that lead to illness and death. The field research analyzed the Food and Nutrition Security conditions of the population of artisanal fishermen from seven municipalities located in Bacia de Campos, state of Rio de Janeiro. The findings are worrisome, as they do not match the resources received by the municipalities, in terms of royalties and special participations, which are added to other transfers and sources of revenue. Food supply programs are urgently needed. The data are part of the Pescarte Project, a partnership among UENF/Petrobras/Ibama.
\end{abstract}

Keywords: municipal resources; artisanal fishermen; food and nutrition security; food insecurity; fishermen's health. 


\section{Introdução}

Este artigo pretende trazer os resultados das pesquisas referentes à Segurança Alimentar e Nutricional (SAN), junto às comunidades pesqueiras localizadas na Bacia de Campos (BC), região Norte do estado do Rio de Janeiro. 0 estudo contempla sete municípios afetados pelas ações do complexo produtivo de petróleo e gás. Busca, assim, aproximar os achados da pesquisa com o conceito mais amplo de saúde, não limitando unicamente à ausência de doença. Trata-se de um esforço de analisar o cotidiano de pescadores artesanais, para que se possa identificar as condições de suas famílias no que diz respeito ao acesso à alimentação de qualidade e às consequências para a saúde desses trabalhadores da região. Tem por objetivo sistematizar os trabalhos e resultados das pesquisas referentes às atividades dos pescadores artesanais dessa região e às suas condições de vida, uma vez que que são considerados "grupos vulneráveis" pelo Diagnóstico Participativo (DP) do Programa de Educação Ambiental da Bacia de Campos (PEA-BC).

Tomamos como referência, portanto, as respostas dos pescadores e de suas famílias, afetadas pelas indústrias de petróleo e gás da Bacia de Campos, em que pesem suas percepções sobre o consumo e acesso a alimentos e sobre as condições de saúde. Vale ressaltar que os pescadores artesanais e as populações ribeirinhas, indígenas, quilombolas, etc. são consideradas prioritárias para as ações de combate à pobreza e à fome pelo Conselho Nacional de Segurança Alimentar e Nutricional (Consea) e, por suposto, para o Ministério de Desenvolvimento Social e Combate à Fome.
Os dados relativos à dimensão "acesso" é que orientaram os argumentos deste artigo, no que tange à SAN junto às comunidades pesqueiras. É um pressuposto básico da SAN, reafirmando a variável renda individual ou familiar como fatores limitadores a esse acesso (Consea, 2004). Dadas a abrangência e profundidade propiciadas pela pesquisa que orienta este artigo, pode-se verificar, por outros ângulos e indicadores, questões ligadas diretas ou indiretamente à SAN, do ponto de vista do "acesso", tais como renda/condições de vida, acesso a políticas públicas de saúde e educação, entre outros.

Em termos conceituais, a legislação assentada na Lei Orgânica de Segurança Alimentar e Nutricional (Losam) considera que a SAN se manifesta "na realização do direito de todos ao acesso regular e permanente a alimentos de qualidade, em quantidade suficiente, sem comprometer o acesso a outras necessidades essenciais [...]". Tem como base o uso de práticas promotoras de saúde, com respeito à "diversidade cultural e que sejam social, econômica e ambientalmente sustentáveis" (Brasil, 2007). A Losan define também as condições de ampliação do acesso, "por meio da produção, em especial da agricultura tradicional e familiar, do processamento, da industrialização, da comercialização" (2004, p. 4). Nessa abrangência conceitual é que se inserem os propósitos do presente artigo, que trata do acesso aos alimentos pelos pescadores artesanais e da vulnerabilidade dessas famílias.

0 caráter variado do enfoque de SAN reflete-se em alguns apontamentos dados pelo Consea com relação a indicadores básicos, sendo agregado em dimensões distintas: (a) produção, (b) disponibilidade de alimentos, 
(c) renda/condições de vida, (d) acesso à alimentação, (e) políticas públicas relacionadas à SAN, (f) saúde e acesso a serviços de saúde e $(\mathrm{g})$ educação. Dessas dimensões, para o desenvolvimento do presente artigo, foi utilizada a dimensão do "acesso à alimentação", usando-se a metodologia da Escala Brasileira de Insegurança Alimentar (Ebia) adotada pelo IBGE no Suplemento de Segurança Alimentar da Pesquisa Nacional de Amostra por Domicílios (Pnad, 2004 e 2009).

As informações tomam por base duas fontes empíricas: a primeira valeu-se dos questionários aplicados durante 0 "Censo" ${ }^{1}$ realizado com os pescadores e suas famílias, em 207 localidades, espalhadas em 39 comunidades, com ao menos três famílias de pescadores, distribuídas nos sete municípios. A segunda considerou as informações obtidas nas reuniões com os pescadores das comunidades.

A metodologia para o desenvolvimento desse artigo toma como base a Ebia, que busca mensurar a percepção das famílias em relação ao acesso aos alimentos. A partir dessa noção, este texto traz alguns dados da Ebia, coletados no campo junto às comunidades pesqueiras. Da mesma forma pretende-se sistematizar os resultados da pesquisa, em termos de interpretação da situação de SAN dos pescadores artesanais da Bacia de Campos. De acordo com essas questões, este artigo propõe trazer à baila a discussão sobre o acesso à alimentação de qualidade por parte de comunidades que, paradoxalmente, produzem alimentos. A maneira mais adequada para isso é ouvir o objeto dessa ação: os pescadores. Com base nessa orientação de caráter mais empírico, é que se pretende dar forma para este artigo.

\section{Caracterização da área de estudo: o campo e a pesquisa}

Apesar dos impactos deletérios no meio ambiente, a pesca constitui-se, ainda, um conjunto de atividades significativas para a economia local, destacando-se como um importante vetor para a promoção de emprego e de renda, em especial para as populações mais vulneráveis que subsistem unicamente dessa atividade tradicional, nos municípios da Bacia de Campos. Nesse espaço geograficamente definido, evidenciam-se três atividades em grande expansão: o turismo, a aquicultura e o petróleo (Walter, 2010). A despeito da radicalidade das transformações econômicas e sociais da paisagem do norte Fluminense e dos muitos problemas ambientais que já se registram na região, a prática da pesca artesanal ainda se beneficia da conformação dos ecossistemas costeiros encontrados ali. Os diversos rios que irrigam o norte do estado do Rio de Janeiro descarregam na costa uma quantidade de nutrientes importantes para a manutenção da cadeia nutricional da vida marinha. Porém, a sobrevivência desse ecossistema depende em grande medida da preservação do meio ambiente, principalmente, das áreas de mangue, que são o berçário de muitas espécies, das atividades da Petrobrás, da qualidade da água dos rios, além do despejo nos mananciais de esgotos e resíduos sólidos não tratados (UFRJ/Soltc/Polo Núatico/Nupem).

Dito isso, cabe definir o recorte espacial que contempla os municípios selecionados a partir de informações coletadas em Reunião 
Temática sobre Pesca e Educação Ambiental na Bacia de Campos. 0 recorte foi definido pelo critério de interferência com a atividade pesqueira na área de influência dos empreendimentos da Petrobras. Tem por objetivo sistematizar os trabalhos e resultados das pesquisas realizadas por pesquisadores do Projeto Pescarte ${ }^{2}$ vinculados à Universidade Estadual do Norte Fluminense Darcy Ribeiro (UENF), em parceria com a Petrobras e o Instituto Brasileiro do Meio Ambiente e dos Recursos Naturais Renováveis (Ibama). Além dos critérios de impacto que orientam o recorte da pesquisa, outros foram adicionados, como o volume médio de pescado desembarcado em toneladas, o número de pescadores e a renda familiar. ${ }^{3}$

0 Quadro 1 apresenta os valores, por critério, relativos à atividade de pesca artesanal em cada um dos municípios. Os dados são trabalhados em percentual, em relação ao total observado para todos os municípios da Bacia de Campos. Essa área se caracteriza por ser uma região de grandes investimentos estatais e privados, além de apresentar uma rica biodiversidade. Compreende uma estrutura sedimentar, localizada na costa brasileira, que se estende do norte do estado do Rio de Janeiro até o sul do estado do Espírito Santo. Trata-se do maior reservatório de petróleo do Brasil, responsável por mais de $80 \%$ de toda a produção offshore, ${ }^{4}$ chegando a 3,031 milhões de barris de óleo equivalente (BOE) por dia. ${ }^{5}$ No Quadro 1 podemos observar a localização dos campos de petróleo descobertos e em atividade de exploração da Bacia de Campos.

Nesse cenário, a Petrobras assume o papel de liderança nesse setor, além de ser a maior empresa brasileira, com destaque na exploração em águas profundas e com elevado potencial de produção. A Bacia de Campos

Quadro 1 - Critérios de seleção de municípios para o Pescarte

\begin{tabular}{|c|c|c|c|c|}
\hline & $\begin{array}{l}\text { Sobreposição das } \\
\text { atividades do espaço } \\
\text { marinho }^{(1)}(\mathrm{em} \%)\end{array}$ & $\begin{array}{c}\text { Volume médio de } \\
\text { pescado desembarcado } \\
\left.\text { por mês } \text { s(2) }^{(e m} \%\right)\end{array}$ & $\begin{array}{c}\text { Número } \\
\text { de pescadores }{ }^{(3)} \\
(\mathrm{em} \%)\end{array}$ & $\begin{array}{c}\text { Renda familiar }{ }^{(4)} \\
\text { (em \%) }\end{array}$ \\
\hline Arraial do Cabo & 2,8 & 17,9 & 7,4 & 42,0 \\
\hline Cabo Frio & 11,9 & 40,0 & 12,6 & 20,0 \\
\hline Campos dos Goytacazes & 0,0 & 20,4 & 20,8 & 76,0 \\
\hline Macaé & 36,4 & 34,2 & 23,3 & 25,0 \\
\hline Quissamã & 0,0 & 16,2 & 1,5 & 48,0 \\
\hline São Francisco de Itabapoana & 40,6 & 24,1 & 23,3 & 68,0 \\
\hline São João da Barra & 8,4 & 35,7 & 9,1 & 27,0 \\
\hline
\end{tabular}

Fonte: PCRs - Petrobras/Projeto Pescarte (2013).

[1] Dados do registro de avistagens das plataformas da Petrobras e abordagens dos navios de pesquisa sísmica dos barcos de pesca artesanal dentro da área de exclusão no período de 2007-2012 na Bacia de Campos.

[2] Dados retirados do Relatório do Projeto de Caracterização Regional da Bacia de Campos (PCR-BC).

[3] Dados do Ministério da Pesca e Aquicultura de 2013.

[4] Dados retirados do Relatório do Projeto de Caracterização Regional da Bacia de Campos (PCR-BC) considerando o número de famílias no município com renda de até $\mathrm{R} \$ 600,00$. 
possui atualmente 55 campos de petróleo, com 826 poços exploratórios. Esses poços estão vinculados a 45 plataformas marítimas, sendo a maioria (41 plataformas) de produção e quatro de processamento. Essa fração do litoral brasileiro é um ambiente socioeconômico complexo, cuja principal atividade econômica é a exploração das reservas de hidrocarbonetos. Operam conjuntamente com a Petrobras outras cinco gigantes corporações do setor petrolífero: (a) HRT Participações em Petróleo; (b) OGPar Óleo e Gás Participações; (c) Chevron Corporation Brasil; (d) Shell Brasil; e (e) Statoil. Destas, as duas primeiras são formadas por consórcios com capital nacional.
Trata-se de um ambiente em que convivem essas grandes corporações que vivem da exploração de petróleo e gás com as comunidades que sobrevivem da pesca artesanal, quechegaram muito antes da descoberta do petróleo na região. É para essas comunidades que se fazem mais prementes intervenções do Estado, via políticas públicas. São, também, "alvos" dos projetos privados de responsabilidade social, mitigação socioambiental e compensação, praticados pelas empresas que "dividem" com eles esse espaço.

No que se refere à ação do Estado brasileiro, para lidar com as questões concernentes à exploração e produção de petróleo

Figura 1 - Mapa da Bacia de Campos

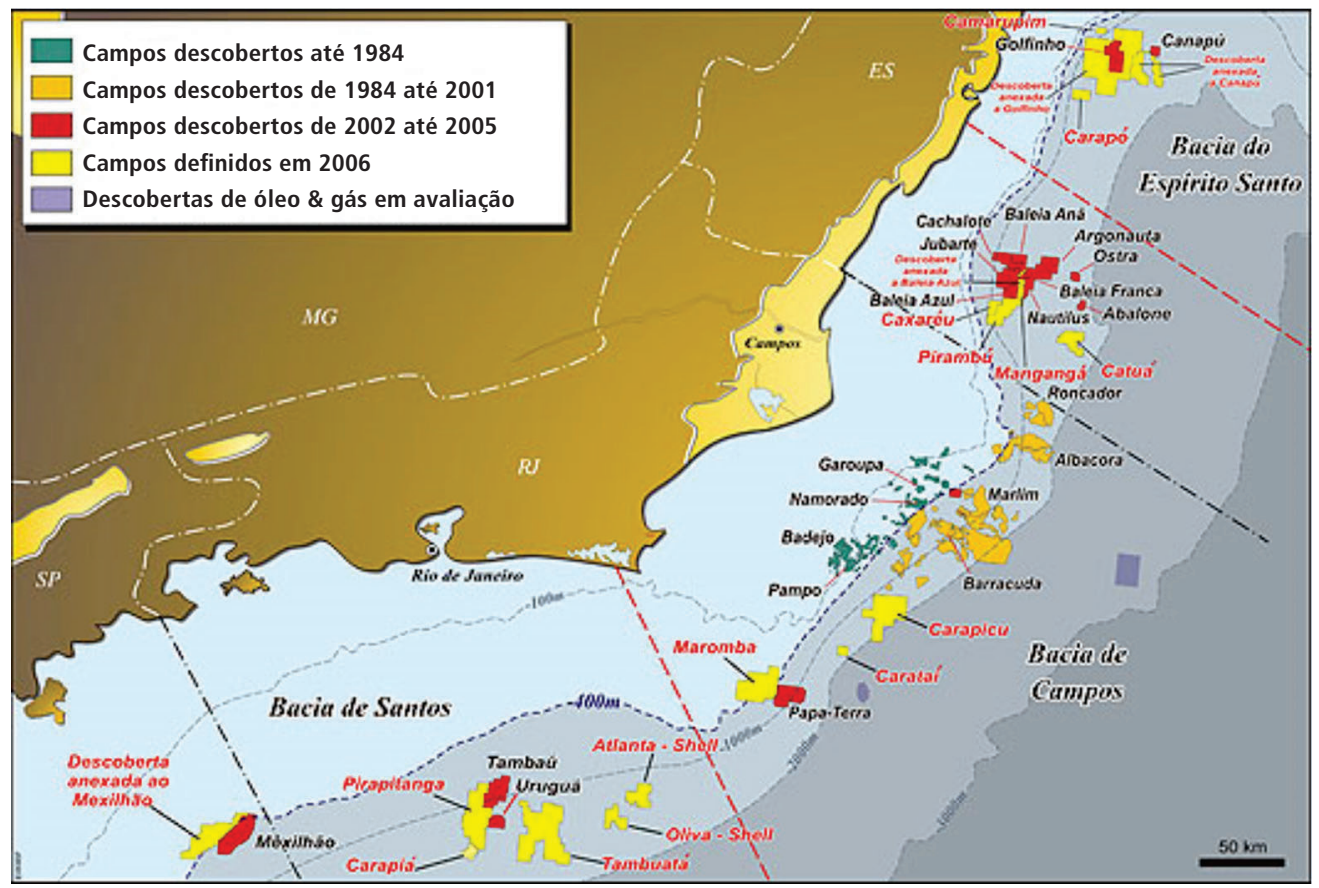

Fonte: http://www.petroleoetc.com.br/ 
e gás, o Ibama se vale da Coordenaçãa Geral de Petróleo e Gás (CGPEG), gerência responsável pela emissão das Notas Técnicas, que regulam, dentre outras questões, os Programas de Educação Ambiental, implementados nas bacias petrolíferas brasileiras. É o braço do Estado que regulamenta e controla as ações de impactos ambientais (e, nesse caso, também social). Vale ressaltar que o Ibama não reconhece as ações pautadas pelo conceito de responsabilidade social como ações de mitigação de impactos. Ou seja, mais um ingrediente que se mistura a esse conjunto de ações, atores e indivíduos em um ambiente extremamente competitivo.
São considerados no cômputo da fiscalização pelo Ibama: a) a gestão ambiental compartilhada, de poder e responsabilidade entre Estado, setores de maior vulnerabilidade socioambiental e outros segmentos sociais; b) o diagnóstico participativo; c) o projeto de mitigação; d) o projeto de compensação; e) 0 programa de educação ambiental; f) a linha de ação, com orientações que permitem o desenvolvimento de projetos de educação ambiental; e g) o projeto de educação ambiental, que é composto pelas atividades que serão desenvolvidas a partir de determinada linha de ação. A Figura 2 destaca os projetos vigentes na Bacia de Campos.

Figura 2 - Mapa dos projetos de educação ambiental na Bacia de Campos

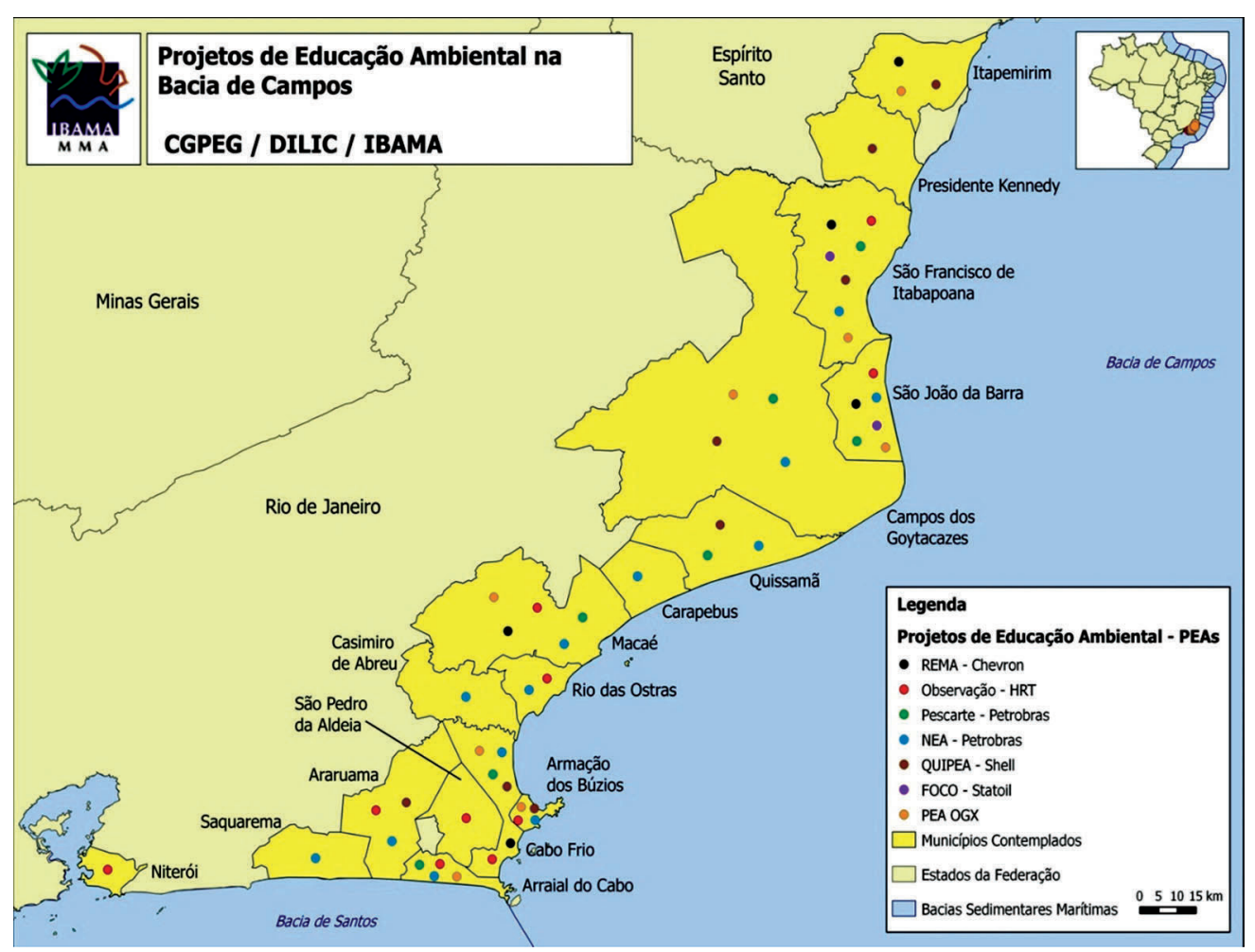

Fonte: CEGPEG/Dilic/lbama. 
Recursos públicos e prioridades de investimentos locais

Uma vez apresentados os critérios para a escolha da região e os municípios a serem estudados, cabe trazer algumas informações adicionais que podem ajudar na construção dos argumentos deste artigo. Para a análise e compreensão das políticas e ações em segurança alimentar e nutricional e dos impactos diretos e indiretos, na promoção da saúde das famílias de pescadores artesanais, é essencial que se evidenciem a capacidade orçamentária desses municípios e o que é destinado às políticas de saúde.

Dito isto, cabe lembrar que esses municípios contam com a chamada "sorte geográfica", que os coloca como receptores privilegiados de royalties de petróleo e participações especiais. Em outras palavras, os propósitos aqui são ilustrar a capacidade potencial desses municípios em responder às necessidades das populações impactadas pela exploração de petróleo e gás e, ainda, priorizar investimentos em políticas públicas que, de alguma forma, possam minimizar os impactos com o futuro-fim da exploração desse recurso não renovável. 0 período analisado, de 2013 a 2015, corresponde ao início da construção da proposta do Projeto Pescarte, junto à Petrobras. 0 Quadro 2 destaca o volume desses recursos para os municípios sob análise.

A queda abrupta no último ano da série é um efeito imediato da redução do repasse dos royalties do petróleo, que foi, em média, de 47\%. Esse cenário não aponta um horizonte tranquilo para esses municípios, que dependem, em larga escala, dessa commodity. ${ }^{6}$ Ainda assim, representa um expressivo aporte financeiro adicional ao orçamento desses municípios, chegando a mais de $70 \%$ de dependência, como é o caso de São João da Barra.

Quadro 2 - Royalties e participações especiais: 2013 a 2015 (em R\$7)

\begin{tabular}{|l|c|c|c|}
\hline \multirow{2}{*}{\multicolumn{1}{|c|}{ Município / Ano }} & \multicolumn{3}{|c|}{ Royalties (+) Participações Especiais } \\
\cline { 2 - 4 } & 2013 & 2014 & 2015 \\
\hline Arraial do Cabo & 44.443 .942 & 46.109 .384 & 24.466 .844 \\
Cabo Frio & 329.883 .324 & 304.805 .596 & 117.911 .385 \\
Campos dos Goytacazes & 1.303 .272 .972 & 1.208 .366 .996 & 550.787 .779 \\
Macaé & 516.455 .723 & 542.656 .872 & 310.654 .749 \\
Quissamã & 94.737 .917 & 95.103 .720 & 49.098 .371 \\
São Francisco de Itabapoana & 8.292 .812 & 8.870 .045 & 5.618 .221 \\
São João da Barra & 228.789 .216 & 237.085 .764 & 140.098 .706 \\
\hline
\end{tabular}

Fonte: http://inforoyalties.ucam-campos.br/ 
De qualquer forma, esse incremento dos royalties compõe o volume de recursos orçamentários que se adiciona às transferências constitucionais, ${ }^{8}$ como pode ser observado no Quadro 3. Vale chamar a atenção para a soma do Fundo de Participação dos Municípios (FPM) e do Fundo de Manutenção e Desenvolvimento da Educação Básica e de Valorização dos Profissionais da Educação (Fundeb), que representa a quase totalidade das transferências, em média 99\%. Para o período analisado, diferentemente do repasse dos royalties, que teve um decréscimo considerável, houve uma elevação média de $7 \%$, nas transferências orçamentárias, entre os anos analisados.

Em que pesem os propósitos do artigo, considerar o volume de recursos disponíveis para dar conta das políticas públicas locais é uma variável essencial para que se possa identificar a capacidade do poder público em atender às demandas da sociedade.

0 Quadro 4 aponta os valores agregados do Sistema Único de Saúde (SUS) repassados a esses municípios, no período analisado. Não se considerou, aqui, a adesão ao tipo de gestão do SUS a que cada município está vinculado. 0 que se pretendeu foi apenas destacar o volume de recursos transferidos para o custeio e investimento na saúde. Mas o que se pode observar é uma elevação média dos repasses, com destaque para Cabo Frio, São Francisco do Itabapoana e São João da Barra. Esses três municípios tiveram repasses expressivos nesses três anos.

0 Quadro 5 apresenta os repasses do SUS por categorias. Esses valores foram desagregados a partir das contas de transferência do SUS. De maneira geral, os repasses do SUS concentram-se nos níveis de "atenção básica" e na "média e alta complexidade", que em conjunto representam, em média, mais de $80 \%$ dos recursos destinados pelo SUS aos municípios.

Os dados apresentados nesta seção referem-se à capacidade orçamentária desses municípios e os valores reais destinados às políticas locais de saúde. No entanto, a despeito do volume de recursos repassados a esses municípios para o custeio e investimentos em saúde, os reflexos, na ponta, não são percebidos de forma tão clara.

0 Gráfico 1 traz as respostas dos entrevistados a respeito dos equipamentos de saúde dos sete municípios de forma agregada. Foi solicitado aos entrevistados que fizessem uma avaliação dando uma nota de zero a dez. Considerando a nota cinco uma avaliação razoável, verifica-se que $35,8 \%$ tem uma avaliação negativa (1 a 4) e menor que a positiva (6 a 10). Por município, com exceção de Quissamã (15,6\%), a avaliação razoável ficou em torno de $20 \%$. Arraial do Cabo, Cabo Frio e Quissamã tiveram a avaliação péssima, em torno de $22 \%$. Nota 10, acima de Campos (37\%), Macaé (15,9\%) e São João da Barra (15,3\%). Regra geral, talvez possamos considerar que a população tem uma avaliação razoável dos equipamentos nos sete municípios, a despeito do volume expressivo de recursos disponíveis para investimentos e custeio com a saúde local. As administrações dos equipamentos não são uniformes nos municípios, talvez isto explique alguns dos extremos de opinião em cada um deles. 
Quadro 3 - Transferências orçamentárias constitucionais aos municípios: 2013 a 2015 (em R\$)

\begin{tabular}{|l|c|c|c|}
\hline \multirow{2}{*}{\multicolumn{1}{|c|}{ Município / Ano }} & \multicolumn{3}{|c|}{ Transferências orçamentárias } \\
\cline { 2 - 4 } & 2013 & 2014 & 2015 \\
\hline Arraial do Cabo & 22.812 .600 & 24.830 .110 & 26.308 .492 \\
Cabo Frio & 130.804 .973 & 142.153 .602 & 148.389 .781 \\
Campos dos Goytacazes & 200.876 .818 & 210.102 .619 & 215.783 .462 \\
Macaé & 134.895 .266 & 148.166 .489 & 159.604 .198 \\
Quissamã & 21.758 .004 & 23.687 .054 & 25.148 .264 \\
São Francisco de Itabapoana & 36.110 .125 & 38.234 .218 & 41.471 .768 \\
São João da Barra & 29.590 .585 & 33.518 .221 & 36.314 .987 \\
\hline
\end{tabular}

Fonte: http://www3.tesouro.gov.br/estados_municipios/municipios_novosite.asp

\section{Quadro 4 - Transferências de recursos do SUS aos municípios: 2013 a 2015 (em R\$)}

\begin{tabular}{|l|c|c|c|}
\hline \multirow{2}{*}{\multicolumn{1}{|c|}{ Município / Ano }} & \multicolumn{3}{|c|}{ Repasses financeiros / SUS } \\
\cline { 2 - 4 } & 2013 & 2014 & 2015 \\
\hline Arraial do Cabo & 4.948 .640 & 5.683 .319 & 5.570 .259 \\
Cabo Frio & 20.637 .905 & 53.488 .962 & 66.561 .303 \\
Campos dos Goytacazes & 113.913 .504 & 132.351 .981 & 137.943 .501 \\
Macaé & 42.765 .692 & 44.375 .408 & 42.563 .033 \\
Quissamã & 6.303 .430 & 6.349 .160 & 6.341 .714 \\
São Francisco de Itabapoana & 3.961 .968 & 6.839 .306 & 7.739 .206 \\
São João da Barra & 3.213 .281 & 4.847 .434 & 6.113 .128 \\
\hline
\end{tabular}

Fonte: http://aplicacao.saude.gov.br/portaltransparencia/index.jsf 


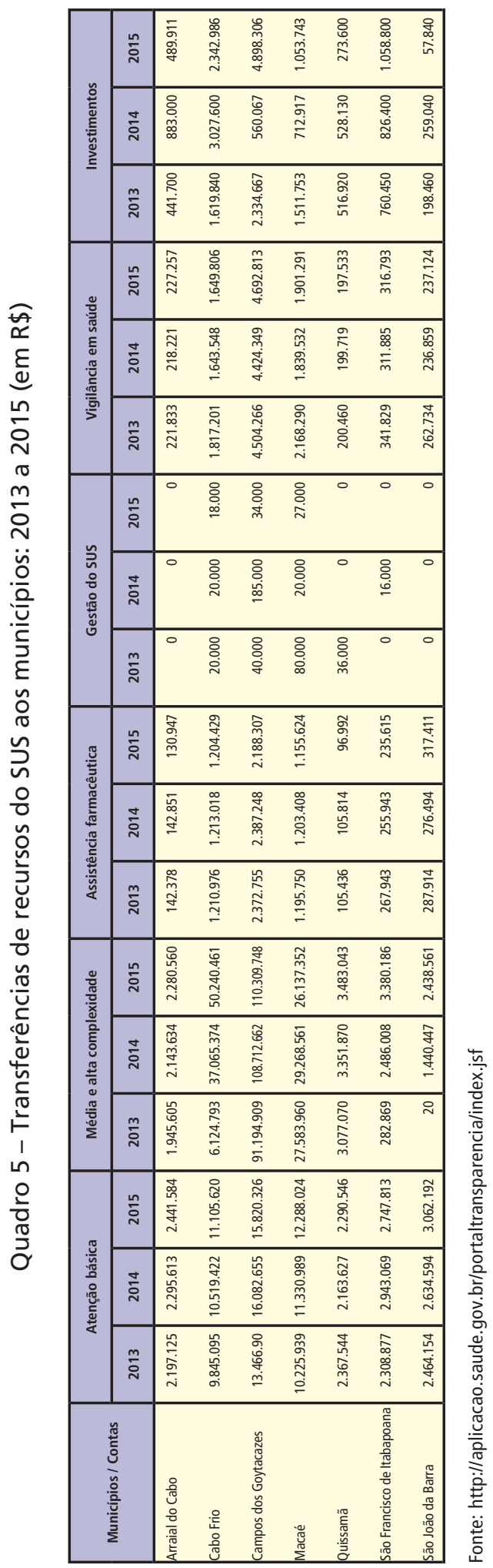


Gráfico 1 - Avaliação dos equipamentos de saúde nos municípios analisados.

(Exemplos: posto de saúde, hospital público, farmácia municipal, ambulância)

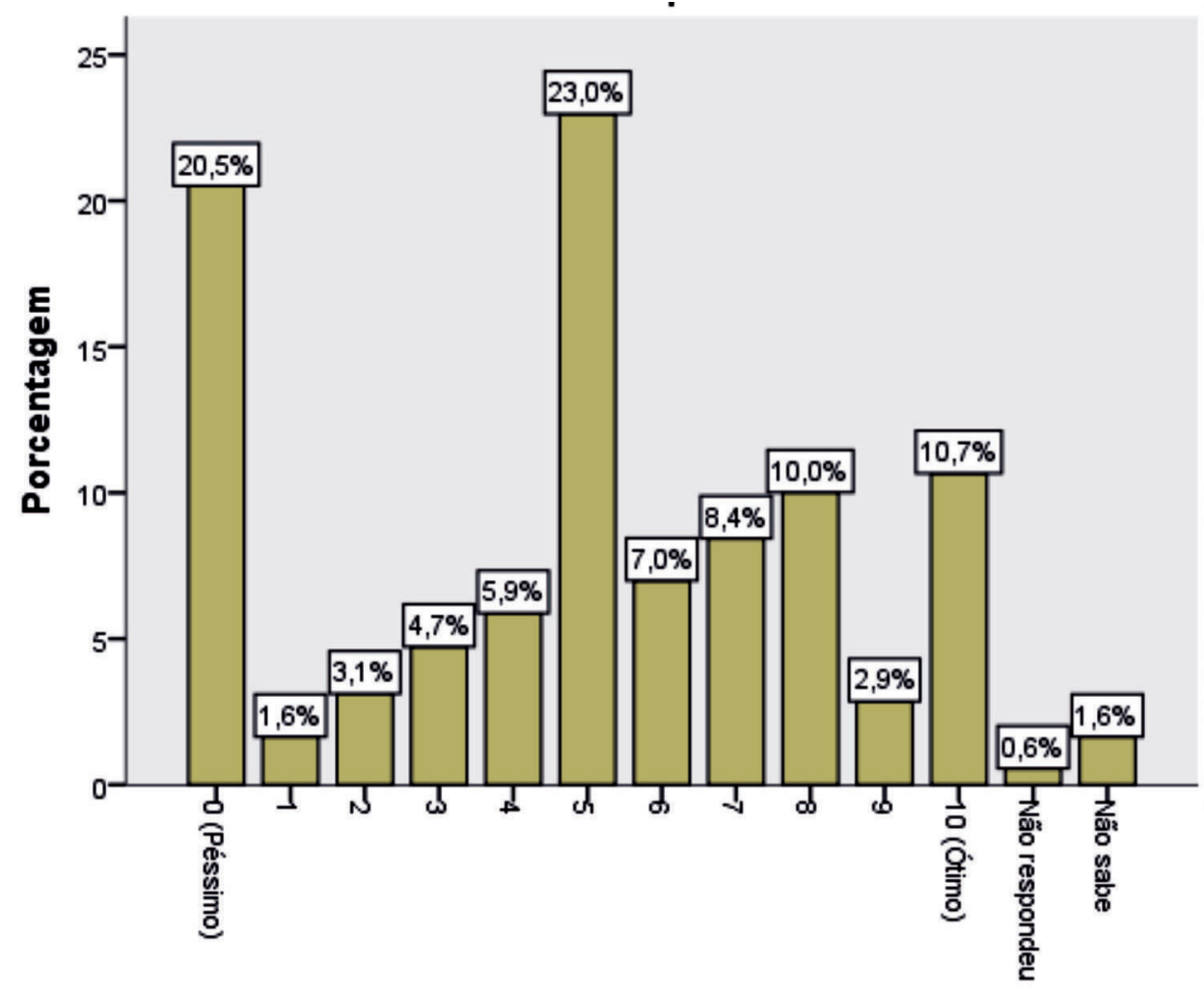

ronte: (enso PtA-rescarte (LUID).

Por fim, para o que se pretende neste artigo, a saúde deve ser expressa no seu conceito mais amplo: "não apenas a ausência de doenças, mas o bem-estar físico e mental". Faz sentido, então, considerar os princípios de segurança alimentar e nutricional, como parte desse entendimento. É o que procuraremos apontar nas próximas seções do artigo, a partir dos recortes espaciais já definidos.
As seções que seguem foram construídas com base nas informações colhidas durante a realização do Censo com os pescadores artesanais (de novembro de 2014 até dezembro de 2015). 0 epicentro da pesquisa é a aplicação da metodologia definida pela Ebia, junto às famílias dos pescadores artesanais nos municípios selecionados. 


\section{Pesquisas de percepção de insegurança alimentar e fome}

Os métodos baseados na percepção da insegurança alimentar foram inicialmente desenvolvidos para aplicação na América do Norte e estavam voltados para as redes de programas de proteção alimentar. Levavam em conta as questões sociais e também biológicas. Pessoas que não tenham meios para adquirir alimentos em quantidade suficiente podem se considerar em insegurança alimentar, ainda que não apresentem sinais clinicamente reconhecíveis de desnutrição. Além disso, mesmo não passando fome, algumas pessoas podem sentir um medo justificável de privações futuras. Representam, portanto, elementos centrais na composição analítica referente à saúde dos trabalhadores (Machado, 2010).

Cabe ressaltar que as pesquisas de ingestão domiciliar de alimentos conseguem perceber o fenômeno da "insegurança alimentar" com maior fidelidade, pois procuram examinar os hábitos de ingestão alimentar das famílias. No Brasil são realizadas como estudos pontuais por institutos de pesquisa e universidades. Uma vantagem desses métodos é que se fundamentam na avaliação direta da ingestão de alimentos. Em função do perfil do Projeto Pescarte, tais métodos não foram utilizados. Portanto, no que se refere à qualidade da alimentação ingerida pelos pescadores, esse dado não foi computado na pesquisa.

A necessidade de disponibilizar indicadores sensíveis de insegurança alimentar que fossem direcionados para a pobreza e não se limitassem às definições clínicas, motivou a realização, nos anos de 1990, de pesquisas que levaram à construção de escalas, metodologicamente complexas e empiricamente fundamentadas de insegurança alimentar. Em termos práticos, esse método consiste na aplicação de questionários que, com uma série de perguntas, cobrem uma escala que vai desde a percepção de preocupação e angústia adiante da possibilidade de não dispor de alimentos regularmente até a percepção de problemas na adequação da dieta (na diversidade e/ou na quantidade de alimentos) que, no limite, levam à fome e a problemas de saúde.

No Brasil, essa metodologia foi aplicada em escala nacional em 2004, 2009 e 2013 pelo IBGE, no âmbito da Pesquisa Nacional de Amostras Domiciliares (Pnad) tendo como um suplemento a Ebia. Esta visa detectar e dimensionar os problemas de insegurança alimentar no País, permitindo classificar as unidades domiciliares em situação de segurança alimentar, esta classificada em leve, moderada ou grave.

Por esse método, a insegurança alimentar é percebida em vários níveis, que vão da preocupação de que o alimento acabe antes que haja dinheiro para comprar mais - dimensão psicológica da insegurança alimentar -, passando, pela insegurança relativa ao comprometimento da qualidade da dieta, sem restrição quantitativa, chegando ao ponto mais grave que é a insegurança quantitativa, situação em que a família passa por períodos concretos de restrição na disponibilidade de alimentos para seus membros, destacando-se a situação em que as crianças são atingidas como a mais grave das condições de insegurança alimentar.

A principal vantagem desse método provém do fato de as medidas qualitativas apreenderem, como elemento essencial, o modo como 
as pessoas mais atingidas percebem a insegurança alimentar. Esse método permite captar, não só as dimensões físicas, mas também as dimensões psicológicas da insegurança alimentar; e permite ainda classificar os domicílios de acordo com sua vulnerabilidade ou nível de exposição à insegurança alimentar. Seus limites são dados pelo caráter "subjetivo" da insegurança alimentar, que dificulta comparações e não permite captar a dimensão da segurança dos alimentos, ou seja, a qualidade sanitária (Pnad, 2013).

Em suma, destaca-se que as diversas metodologias de medição de segurança alimentar são complementares ao evidenciar distintos níveis de agregação geográfica e demográfica, bem como seus indicadores diretos e indiretos. Esses indicadores refletem o sentimento de insegurança alimentar dos entrevistados, de forma a fazer uma gradação em relação à sua segurança de obter e consumir alimentos. Trata-se de uma escala de 14 perguntas. 0 número de respostas "sim" permite uma classificação que vai da segurança alimentar até a insegurança grave. 0 Quadro 6 apresenta as questões centrais para que se possa identificar a gradação da percepção dos indivíduos em relação à sua insegurança alimentar.

0 processo de análise dos resultados da aplicação da tabela Ebia pode seguir dois modelos distintos. 0 primeiro (Tabela 1) avalia a presença de respostas "sim" ao questionário, considerando sua presença como um fator revelador das condições de baixa ou nenhuma nutrição entre a população investigada.
A outra consiste na leitura individual das respostas às 14 perguntas formuladas aos entrevistados. Esse método possibilita a identificação percentual das famílias que são submetidas às condições de privação severa de alimentos, como é o caso apontado pelas questões 7 e 13 da tabela Ebia. Seguiremos à segunda análise proposta.

A partir dessas questões, é possível mensurar o que se tem sobre a percepção em relação ao acesso à alimentação. É uma medida, portanto, da expectativa dos indivíduos. Os resultados medidos pela Ebia mostram uma associação forte entre a insegurança alimentar e os baixos rendimentos. A participação da sociedade civil tem um papel essencial na condução das políticas públicas de SAN. É nesses termos que ganham cada vez mais importância os conselhos participativos. Isso se evidencia no fato de que, dos sete municípios analisados, apenas dois não têm conselhos de SAN: Arraial do Cabo e São Francisco do Itabapoana. Ainda nesses termos relativos à participação da sociedade civil na condução das políticas de SAN, pode-se afirmar, com certa segurança, que a pesquisa desenvolvida pelo Projeto Pescarte, conduzida pela UENF/Petrobras/Ibama, seja a de maior abrangência, em uma comunidade específica - caracterizada entre povos e comunidades tradicionais considerados pelo Consea Nacional. Nas próximas seções serão apresentados os resultados da aplicação da metodologia da Ebia, parte integrante dos questionários do Censo junto às localidades pesqueiras cobertas pelo Projeto Pescarte. 


\section{Quadro 6 - Questionário da Escala Brasileira de Insegurança Alimentar}

\begin{abstract}
1) Nos últimos três meses, os moradores deste domicílio tiveram a preocupação de que a comida acabasse antes que tivessem dinheiro para comprar mais comida?
\end{abstract}

2) Nos últimos três meses, os alimentos acabaram antes que os moradores deste domicílio tivessem dinheiro para comprar mais comida?

3) Nos últimos três meses, os moradores deste domicílio ficaram sem dinheiro para ter uma alimentação saudável e variada?

4) Nos últimos três meses, os moradores deste domicílio comeram apenas alguns poucos tipos de alimentos que ainda tinham, porque o dinheiro acabou?

5) Nos últimos três meses, algum morador de 18 anos ou mais de idade deixou de fazer alguma refeição, porque não havia dinheiro para comprar a comida?

6) Nos últimos três meses, algum moradores de 18 anos ou mais de idade comeu menos do que achou que devia, porque não havia dinheiro para comprar comida?

7) Nos últimos três meses, algum morador de 18 anos ou mais de idade sentiu fome, mas não comeu, porque não tinha dinheiro para comprar comida?
8) Nos últimos três meses, algum morador de 18 anos ou mais de idade ficou um dia inteiro sem comer ou teve apenas uma refeição ao dia, porque não tinha dinheiro para comprar comida?

9) Nos últimos três meses, os moradores com menos de 18 anos de idade não puderam ter uma alimentação saudável e variada, porque não havia dinheiro para comprar comida?

10) Nos últimos três meses, algum morador com menos de 18 anos de idade comeu menos do que você achou que devia porque não havia dinheiro para comprar a comida?

11) Nos últimos três meses, foi diminuída a quantidade de alimentos das refeições de algum morador com menos de 18 anos de idade, porque não havia dinheiro suficiente para comprar a comida?

12) Nos últimos três meses, algum morador com menos de 18 anos de idade deixou de fazer alguma refeição, porque não havia dinheiro para comprar a comida?

13) Nos últimos três meses, algum morador com menos de 18 anos de idade sentiu fome, mas não comeu, porque não havia dinheiro para comprar mais comida?

14) Nos últimos três meses, algum morador com menos de 18 anos de idade ficou um dia inteiro sem comer ou teve apenas uma refeição ao dia, porque não havia dinheiro para comprar comida

Fonte: Núcleo de Estudos em Pesquisa em Alimentação/MDS, 2010.

Respostas Sim (1) e Não (0)

Escore para classificação = somatória de respostas positivas (de 0 a 14)

Tabela 1 - Pontos de corte para classificação dos domicílios

\begin{tabular}{l|c|c}
\hline \multirow{2}{*}{ Classificação } & \multicolumn{2}{|c}{ EBIA } \\
\cline { 2 - 3 } & Domicílios com menores de 18 anos & Domicílios sem menores de 18 anos \\
\hline Segurança alimentar & 0 & 8 \\
Insegurança leve & $1-5$ & $1-3$ \\
Insegurança moderada & $6-9$ & $4-5$ \\
Insegurança grave & $10-14$ & $6-8$ \\
\hline
\end{tabular}

Fonte: Núcleo de Estudos em Pesquisa em Alimentação/MDS (2010). 


\section{Resultados do censo}

Ao longo desta seção, serão apresentados os resultados encontrados pelas pesquisas considerando o seu limite temporal. Parte dos argumentos que justificam a escolha desse público pode ser apontada pelo próprio Ministério da Pesca e Aquicultura (MPA), ao destacar que a pesca artesanal é uma das principais atividades sociais, econômicas e ambientais realizadas no Brasil, com um milhão de pescadores artesanais e com cerca de 3,5 milhões de pessoas vivendo, direta ou indiretamente, da renda na atividade pesqueira. Contudo, esse número pode conter variações. Como no caso da região lindeira à Bacia de Campos, os dados do IBGE (Censo, 2010) apresentam um total de 3.020 pescadores, enquanto as Colônias de Pesca afirmam possuir, em seus cadastros, 14.730 pescadores.

Vale ressaltar que os dados do Censo foram obtidos por meio de um questionário amplo, construído e aplicado pelo Projeto Pescarte, junto a todas as localidades de pescadores artesanais dos sete municípios pesquisados na Bacia de Campos. Esse questionário foi dividido em dez blocos temáticos. ${ }^{9}$ Dentre eles, a SAN foi abordada no bloco relativo ao "Inquérito Alimentar", tendo por base as questões já validadas pela Ebia. Foram utilizadas também, informações coletadas em outros blocos do questionário, como "Identificação Socioeconômica", "Caracterização Familiar" e "Avaliação de Serviços Públicos".

Nas tabelas a seguir, apresentamos os resultados das perguntas 1, 7 e 13 da Ebia, pois, elas vão da condição leve de insegurança alimentar, que é o temor da falta de alimentos, à condição mais severa, que representa a completa falta de alimentos por, pelo menos, um dia nos últimos três meses. $A$ seguir se observa o percentual de famílias de pescadores artesanais, distribuídos nos sete municípios, no que tange a falta de alimento.

A Tabela 2 aponta para uma situação extremamente grave quando consideramos que estamos falando de produtores de alimentos, pois, temem passar forme. Como pode-se

Tabela 2 - Respostas questão Ebia-1

\begin{tabular}{l|c|c|c|c}
\hline \multirow{2}{*}{$\begin{array}{l}\text { Município do estudo } \\
\text { Campos dos Goytacazes }\end{array}$} & \multicolumn{2}{|c|}{$\begin{array}{c}\text { Nos últimos três meses, os moradores deste domicílio tiveram } \\
\text { a preocupação de que a comida acabasse antes que tivessem } \\
\text { dinheiro para comprar mais comida? }\end{array}$} & Total (\%) \\
\cline { 2 - 4 } Macaé & 62,4 & Não (\%) & Não respondeu (\%) & 100,0 \\
São Francisco do Itabapoana & 31,9 & 37,0 & 0,6 & 100,0 \\
São João da Barra & 37,5 & 65,3 & 0,5 & 100,0 \\
Arraial do Cabo & 45,3 & 62,0 & 0,2 & 100,0 \\
Cabo Frio & 33,8 & 54,5 & 2,3 & 100,0 \\
Quissamã & 46,7 & 63,9 & 3,1 & 100,0 \\
\hline
\end{tabular}

Fonte: Censo PEA-Pescarte/2015. 
observar, os municípios de Campos dos Goytacazes, Cabo Frio e São João da Barra apresentam, respectivamente, as situações mais graves, pois $62,4 \%, 46,7 \%$ e $45,3 \%$ das famílias temem passar forme pela falta de recursos para aquisição de alimentos, antes do término do mês. Os demais municípios apresentam, também, resultados expressivos, e o município de Macaé apresenta o menor resultado, 31,9\%.

Na Tabela 3, encontram-se os dados de restrição alimentar severa, caracterizada pelo fato de os indivíduos terem experimentado a ausência de alimentos por pelo menos um dia sem terem recursos para providenciar sua alimentação. Assim, Campos dos Goytacazes, reconhecido como o município da região com maiores recursos, provenientes das rendas petrolíferas, atingindo a cifra de $\mathrm{R} \$ 2,4$ bilhões ao ano, apresenta um percentual de $16,7 \%$ de famílias de pescadores artesanais com membros maiores de 18 anos que sentiram fome e não puderam comer pela ausência de dinheiro para comprar comida. Em seguida, Cabo Frio apresenta um percentual de 10,1\% de indivíduos famélicos, e Arraial do Cabo revela que 9\% de pessoas acima de 18 anos sentiram fome sem terem condições financeiras para saciar sua vontade de comer. Os demais municípios, Macaé, São João da Barra, São Francisco e Quissamã, apresentam, respectivamente, 7,2\%, 6,9\%, $5,9 \%$ e $2,8 \%$, mas, apesar de terem resultados mais baixos, não deixam de apresentar situações preocupantes.

Já, a Tabela 4, que corresponde à $13^{a}$ pergunta da Ebia, apresenta a situação em que indivíduos menores de 18 anos sofreram restrição alimentar severa. Campos dos Goytacazes apresenta 8,3\%, e Macaé e Arraial do Cabo, $5,8 \%$ e 5,7\%, respectivamente, os maiores índices. Contudo, em se tratando da condição de ausência de alimentos, qualquer indicativo deve ser considerado grave, como ocorre nos municípios de Cabo Frio, com 4,1\%, São João da Barra, com 3,9\%, Quissamã, com 2,7\% e

Tabela 3 - Respostas questão Ebia-7

\begin{tabular}{l|c|c|c|c}
\hline \multirow{2}{*}{ Município do estudo } & \multicolumn{2}{|c|}{$\begin{array}{c}\text { Nos últimos três meses, algum morador de 18 anos ou mais de } \\
\text { idade sentiu fome, mas não comeu, porque não tinha dinheiro } \\
\text { para comprar comida? }\end{array}$} & Total (\%) \\
\cline { 2 - 4 } & Sim (\%) & Não (\%) & Não respondeu (\%) & 100,0 \\
\hline Campos dos Goytacazes & 16,7 & 82,5 & 0,8 & 100,0 \\
Macaé & 7,2 & 90,4 & 1,0 & 100,0 \\
São Francisco do Itabapoana & 5,9 & 93,1 & 0,5 & 100,0 \\
São João da Barra & 6,9 & 92,7 & 2,9 & 100,0 \\
Arraial do Cabo & 9,0 & 88,2 & 3,1 & 100,0 \\
Cabo Frio & 10,1 & 86,8 & - & 100,0 \\
Quissamã & 2,8 & 97,2 & & \\
\hline
\end{tabular}

Fonte: Censo PEA-Pescarte/2015. 
Tabela 4 - Respostas questão Ebia-13

\begin{tabular}{|c|c|c|c|c|c|}
\hline \multirow[t]{2}{*}{ Município do estudo } & \multicolumn{4}{|c|}{$\begin{array}{l}\text { Nos últimos três meses, algum morador com menos de } 18 \text { anos de idade } \\
\text { sentiu fome, mas não comeu, porque não havia dinheiro para comprar } \\
\text { mais comida? }\end{array}$} & \multirow[t]{2}{*}{ Total (\%) } \\
\hline & $\operatorname{Sim}(\%)$ & Não (\%) & Não respondeu (\%) & Não sabe (\%) & \\
\hline Campos dos Goytacazes & 8,3 & 87,8 & 3,6 & 0,4 & 100,0 \\
\hline Macaé & 5,8 & 90,5 & 2,9 & 0,7 & 100,0 \\
\hline São Francisco do Itabapoana & 1,9 & 95,8 & 2,1 & 0,2 & 100,0 \\
\hline São João da Barra & 3,9 & 93,6 & 2,5 & - & 100,0 \\
\hline Arraial do Cabo & 5,7 & 87,9 & 5,7 & 0,6 & 100,0 \\
\hline Cabo Frio & 4,1 & 87,6 & 7,0 & 1,2 & 100,0 \\
\hline Quissamã & 2,7 & 94,7 & 2,7 & - & 100,0 \\
\hline
\end{tabular}

Fonte: Censo PEA-Pescarte/2015.

São Francisco do Itabapoana, com 1,9\%. Cabe ressaltar que os dados apresentados são, percentualmente, quase a metade daqueles verificados pelos indivíduos com idade acima de 18 anos. Isso pode ser um indicativo de que os indivíduos adultos buscam, na maioria das vezes, alimentar primeiramente as crianças e os adolescentes. Essa realidade informa que, quando constatamos a presença da fome em menores de 18 anos, aqueles indivíduos com idade superior já estão em processo de restrição alimentar há mais tempo.

Por fim, tem-se, dessa forma, que os dados relativos a SAN dos pescadores artesanais de Bacia de Campos, apontados pela pesquisa, confirmam a situação de restrição alimentar. Pode-se dizer, assim, que boa parte do que foi evidenciado pode ser reflexo de insuficiência de renda para adquirir alimentos em quantidade suficiente.

\section{Considerações finais}

A proposta deste artigo foi conciliar os objetivos centrais do Projeto Pescarte, que tem como foco a educação ambiental das famílias dos pescadores afetados pelas atividades da Petrobras na Bacia de Campos, com as condições básicas de saúde. Nesse sentido, buscou-se trazer os resultados coletados pela pesquisa junto aos pescadores artesanais dos sete municípios da Bacia de Campos, de modo que se pudesse chamar a atenção para uma questão relevante que afeta a saúde dessas pessoas. Para tanto, o mote utilizado foi o acesso a alimentos pelas famílias cobertas pelo Projeto. Os dados relativos à Segurança Alimentar e Nutricional (SAN) dos pescadores artesanais da Bacia de Campos apontam a necessidade de se tomar medidas que possam debelar a insegurança percebida pelas famílias 
dos pescadores quanto a se alimentar regularmente, em quantidade suficiente e qualidade. A incerteza, com relação a ter o que comer, permeia o cotidiano de um número expressivo de pescadores. E as respostas evidenciam que as famílias sofrem por saber que amanhã poderá faltar alimentação suficiente ou por sua falta regularmente, causando-Ihes sobressaltos e angústias permanentes. Além dos efeitos psicológicos desse sentimento.

0 que se tem como resultado analíti$\mathrm{co}$, em que pesem os recortes definidos pelo escopo da pesquisa, é que parte das famílias não se alimenta bem. Não só por insuficiência de renda, mas por se alimentar mal, despendendo seus escassos recursos financeiros em alimentos prejudiciais à saúde, gordurosos e com excesso de açúcar. Tem, portanto, um impacto direto na saúde dessas famílias. Afinal, se "uma boa saúde começa pela boca", tal condição está longe de ser o ideal para um conjunto de pecadores artesanais da Bacia de Campos. Pois bem, a produção de alimentos e seu consumo também podem ser trabalhados pelo foco da questão ambiental: a alimentação dos pescadores e o alimento produzido por eles dentro de critérios sustentáveis para o meio ambiente e que podem melhorar sua renda. Não é demais dizer que o mercado, hoje conhecido como "justo", tem valorado, com dignidade, os alimentos produzidos dessa forma, o que atende conjuntamente duas metas do Pescarte: educação ambiental e melhoria de renda dos pescadores.

\section{Mauro Macedo Campos}

Universidade Estadual do Norte Fluminense Darcy Ribeiro, Programa de Pós-Graduação em Sociologia Política. Campos dos Goytacazes, RJ/Brasil.

mauromcampos@yahoo.com.br

\section{Moisés Machado}

Universidade Estadual do Norte Fluminense Darcy Ribeiro, Programa de Pós-Graduação em Sociologia Política. Campos dos Goytacazes, RJ/Brasil.

moisesm@oi.com.br

\section{Geraldo Márcio Timóteo}

Universidade Estadual do Norte Fluminense Darcy Ribeiro, Laboratório de Estudos do Espaço Antrópico. Campos dos Goytacazes, RJ/Brasil.

geraldotimoteo@gmail.com

\section{Paulo Belchior Mesquita}

Universidade Estadual do Norte Fluminense Darcy Ribeiro, Centro de Ciências do Homem, Laboratório de Estudos da Sociedade Civil e do Estado. Campos dos Goytacazes, RJ/Brasil. paulo_mesquita@ymail.com 


\section{Notas}

(1) Os dados do Censo foram considerados, para este artigo, até o dia 17 de dezembro de 2015, tendo o seu início em novembro de 2014.

(2) O Pescarte é um projeto de mitigação ambiental e obedece aos parâmetros estabelecidos em Plano de Trabalho formulado a partir das condicionantes oriundas da Nota Técnica CGPEG/ Dilic/Ibama no 1/2010, Linha "A", e do Diagnóstico Participativo do PEA-BC. O projeto é fruto do Plano de Caracterização Regional da Bacia de Campos (PCR-BC) e tem como objetivo a execução de ações de mitigação decorrentes da exploração e produção de petróleo e gás na Bacia de Campos (BC), desenvolvidas pela Petrobras, tendo como foco as comunidades de pescadores artesanais circunscritas em sete municípios da $B C$ no estado do Rio de Janeiro.

(3) Os critérios relativos ao "volume médio de pescado desembarcado" e "renda familiar" foram usados, pelo Pescarte, como subsídio de dados do Projeto de Caracterização Regional da Bacia de Campos (PCR-BC).

(4) As plataformas de extração de petróleo podem ser no continente, em terra firme, sendo denominadas "plataforma onshore", ou no mar, que são as chamadas "plataforma offshore", possuindo uma estrutura moderna de perfuração em alto mar, abrigando trabalhadores e equipamentos necessários na perfuração de poços, além da extração de petróleo e gás. Tais plataformas podem ser fixas no solo marinho ou flutuantes.

(5) O dado de 3,031 milhões de barris de óleo equivalente (BOE) por dia refere-se à produção recente, extraído como um elemento informativo para o artigo em 4 de abril de 2015. Ver em: http://www.msatual.com.br/2015/04/03/petroleo-e-gas-no-pais-alcancou-a-marca-de-3031milhoes-de-barris/

(6) Recentemente o barril de petróleo atingiu a sua pior cotação em mais de uma década, fechando abaixo de US\$35.00 o barril. Ver em http://g1.globo.com/economia/mercados/noticia/2016/01/ petroleo-fecha-abaixo-de-us-35-pela-1-vez-em-11-anos.html.

(7) Vale ressaltar que os valores em reais apresentados nesta e nas demais tabelas não foram deflacionados. Correspondem à moeda corrente do respectivo ano.

(8) A composição das transferências constitucionais são: Fundo de Participação dos Municípios (FPM); Imposto sobre propriedadeTerritorial Rural (ITR); Imposto sobre Operações Financeiras (IOF); Imposto sobre propriedade Territorial Rural (ITR); Lei Complementar 87/1996, Lei Kandir; Contribuições de Intervenção no Domínio Econômico (CIDE); Auxílio Financeiro para Fomento das Exportações (FEX); Fundo de Manutenção e Desenvolvimento do Ensino Fundamental e de Valorização do Magistério (Fundef); Fundo de Manutenção e Desenvolvimento da Educação Básica e de Valorização dos Profissionais da Educação (Fundeb).

(9) O questionário Pescarte contou com os seguintes blocos de questões: Bloco 1: Identificação socioeconômica - Características demográficas; Bloco 2: caracterização familiar; Blocos 3 e 4: Avaliação de serviços públicos; Bloco 5: Trabalho e trajetória profissional; Bloco 6: Caracterização da atividadepesqueira; Bloco 7: Capital social e laços de família; Bloco 8: Gênero; Bloco 9: Caracterização da educação ambiental na Bacia de Campos; Bloco 10: Inquérito alimentar. 


\section{Referências}

BRASIL (2006). Lei Orgânica de Segurança Alimentar Nutricional. Lei no 11.346, de 15 de setembro de 2006. Cria o Sistema Nacional de Segurança Alimentar e Nutricional-SISAN com vistas em assegurar o direito humano à alimentação adequada e dá outras providências. Diário Oficial da União.

(2007). Insegurança Alimentar no Brasil: do Desenvolvimento do Instrumento de Medida aos Primeiros Resultados Nacionais. Avaliação dos Políticas e Programas do MDS - Resultados. Ministério do Desenvolvimento Social e Combate à Fome, DMS, Brasília/DF.

(2014). Ministério da Pesca e Aquicultura. Pesca Artesanal. 2014. Disponível http://www.mpa. gov.br/index.php/pesca/artesanal. Data de acesso: 21/07/2014.

CENSO PEA-PESCARTE (2015). Projeto de Mitigação Ambiental PETROBRAS/IBAMA/UENF. Campos dos Goytacazes.

CONSEA NACIONAL (2004). Presidência da República, Conselho Nacional de Segurança Alimentar e Nutricional. Princípios e Diretrizes de Uma Política Nacional de Segurança Alimentar e Nutricional. CONSEA, Brasília/DF.

(2007). Construindo um sistema de monitoramento da realização progressiva do Direito Humano à Alimentação Adequada (DHAA), no contexto do Sistema Nacional da Segurança Alimentar e Nutricional (SISAN). Consea, Brasília/DF.

CUNHA, A. R. A. A e LEMOS, M. B. (1996). Segurança alimentar sob o prisma das políticas urbanas de abastecimento. Texto para discussão, n. 113. Belo Horizonte, Cedeplar/UFMG.

FAO (2014). O Estado da Segurança Alimentar e Nutricional no Brasil: Um Retrato Multidimensional. Disponível em: https://www.fao.org.br/download/SOFI_p.pdf. Data de acesso: 27 jun 2015.

IBGE (2004, 2009 e 2013). Suplemento de Segurança Alimentar. Pesquisa Nacional de Amostra por Domicílio (PNAD). Disponível em: http://www.ibge.gov.br/home/estatistica/populacao.

MACHADO, M. (2010). Acesso a Alimentação, Projetos Indicadores em SAN. Belo Horizonte, Ipead/ UFMG.

MACHADO, M; MENICCUCI, T. M. G e SOUZA, Z. B. (2009). A experiência da política de segurança alimentar de Belo Horizonte: parcerias, participação e controle social. Revista Observatório do Milênio, ano 2, n. 1, Secretaria Municipal de Planejamento, Orçamento e Informação da Prefeitura de Belo Horizonte/MG.

PANIGASSI, G. et al. (2008). Insegurança alimentar como indicador de iniquidade: análise de inquérito populacional. Cad. Saúde Pública, v. 24, n. 10, pp. 2376-2384.

PESSANHA, L. D. R. (2002). A experiência brasileira em políticas públicas para a garantia do direito ao alimento. Rio de Janeiro, IPEA.

PESSANHA, L. D. R. et al. (2008). Indicadores para avaliar a Segurança Alimentar e Nutricional e a garantia do Direito Humano à Alimentação: metodologias e fontes de dados. Anpocs, Caxambu/ MG.

SEGALL-CORRÊA, A. M. e MARIN-LEON, L. A (2009). Segurança alimentar no Brasil: proposição e usos da Escala Brasileira de Medida da Insegurança Alimentar (Ebia) de 2003 a 2009. Segurança Alimentar e Nutricional, v. 16, n. 2, pp. 1-19. 
UFRJ-MAR/SOLTEC/POLO NÁUTICO/NUPEM/FINEP (2006). Pesquisa-ação na Cadeia Produtiva da Pesca em Macaé Papesca/Macaé - Relatório Final. Disponível em: http://www.soltec.poli.ufrj. br/RelatorioFINEP-VFinal.pdf. Acesso em: 9 nov 2015.

WALTER, T. (2010). Novos Usos e Novos Mercados: Qual sua influência na dinâmica da cadeia produtiva dos frutos do mar oriundos da pesca artesanal? Tese de Doutorado. Rio de Janeiro, Universidade Federal Rural do Rio de Janeiro.

Texto recebido em 8/jan/2016

Texto aprovado em 10/abr/2016 
